nosis. If acute GVHD is clinically suspected, this may be confirmed immediately by skin biopsy and by HLA typing of the peripheral blood lymphocytes. Once GVHD is documented, aggressive cytolytic therapy to destroy donor lymphocytes seems to be the only therapeutic option.

\section{REFERENCES}

1. Prop J, Wildevuur CRH, Nieuwenhuis P. Acute graft-versushost disease after lung transplantation. Transplant Proc 1989; 21:2603-4.

2. Wood H, Higenbottam T, Joysey V, et al. Graft versus host disease after human heart-lung transplantation. In: Proceed- ings of the XIII International Congress of the Transplantation Society. San Francisco: August 19-24, 1990; p. 364.

3. Hunt BJ. Graft versus host disease in heart and/or lung transplantation. In: Rose ML, Yacoub MH, editors. Immunology of heart and lung transplantation. London: Arnold; 1993. p. 261-75.

4. Herman JG, Beschorner WE, Baugham KL, et al. Pseudograft-versus-host disease in heart and heart-lung recipients. Transplantation 1988;46:93-8.

5. Joysey V, Wood H, Ramsbottom S, et al. Lymphocyte chimaerism after solid organ transplantation. Transplant Proc 1992; 24:2519-22.

\title{
RUPTURE OF INFLOW CONDUITS IN THE TCI-HEARTMATE SYSTEM
}

\author{
Hans H. Scheld, MD, ${ }^{\mathrm{a}}$ Rasjid Soeparwata, MD, ${ }^{\mathrm{a}}$ Christof Schmid, MD, ${ }^{\mathrm{a}}$ Michael Loick, MD, ${ }^{\mathrm{b}}$ Michael Weyand, MD, \\ and Dieter Hammel, MD, ${ }^{a}$ Münster, Germany
}

Improved surgical techniques and sophisticated postoperative care have led to impressive long-term results for the implantable left ventricular assist device (LVAD) as a bridge to transplantation in patients with end-stage cardiac failure. However, all of the currently used assist devices are less than perfect, and only about $70 \%$ of patients supported with an LVAD eventually undergo transplantation. Apart from preoperative multiorgan failure, bleeding, thromboembolism, and infection still jeopardize the successful outcome and contribute to significant postoperative morbidity, because most of the patients have one or more of these adverse events. We report on a life-threatening complication, which has occurred in two of our six patients with the TCI-HeartMate system (Thermo Cardiosystems, Inc., Woburn, Mass.) and which seems to occur more often than expected. ${ }^{1}$

\section{Clinical summaries}

PATIENT 1. A 56-year-old male patient with end-stage ischemic heart disease was awaiting heart transplantation. Because of recurrent left ventricular decompensation and ongoing New York Heart Association class IV status, we decided to implant the TCI system as a bridge to trans-

From the Departments of Thoracic and Cardiovascular Surgery, ${ }^{\mathrm{a}}$ Anesthesia and Operative Intensive Care Medicine, ${ }^{b}$ Westfalian Wilhelms-University, Münster, Germany.

Received for publication Nov. 12, 1996; accepted for publication Jan. 15, 1997.

Address for reprints: Hans $H$. Scheld, MD, Klinik und Poliklinik für Thorax-, Herz- \& Gefäßchirurgie, Westfälische WilhelmsUniversität Münster, Albert-Schweitzer-Str. 33, 48129 Münster, Germany.

J Thorac Cardiovasc Surg 1997;114:287-9

Copyright (C) 1997 by Mosby-Year Book, Inc.

$0022-5223 / 97 \$ 5.00+0 \quad \mathbf{1 2 / 5 4 / 8 0 4 0 3}$ plantation. The patient fulfilled all criteria defined for patient selection. The LVAD was implanted with the heart beating, as has recently been described for the Novacor system (Baxter Healthcare Corp, Novacor Div., Oakland, Calif.). ${ }^{2}$ Initially, the postoperative course was uneventful except for placement of a chest tube for left-sided pleural effusion. The patient recovered well, with a pump output of 7 to $8 \mathrm{~L} / \mathrm{min}$, and organ function steadily improved. He was fully mobile when blood suddenly poured from the cutaneous exit of the drive line on postoperative day 22 . A chest $\mathrm{x}$-ray film revealed widening of the mediastinal structures but otherwise normal findings. After a sudden drop of the hemoglobin and hematocrit levels, the preperitoneal device pocket was reopened and massive clots poured out, suggesting severe bleeding. Immediate sternotomy was performed and extracorporeal circulation was instituted on an emergency basis. A transverse tear of 2 to $3 \mathrm{~mm}$ within the inflow conduit close to the proximal edge of the metallic cage support, protecting the Dacron conduit, became evident. Because of the massive blood loss, the left atrial filling pressure decreased and air was sucked into the lacerated Dacron tube of the inflow conduit. The LVAD was stopped immediately and the tear in the inflow conduit closed with felt-patch reinforced sutures, French glue, ${ }^{3,4}$ and double wrapping with a size 24 Dacron prosthesis. TCI LVAD support was reinstituted and no residual leakage was present. Despite meticulous deairing of the LVAD, massive cerebral air embolism caused brain death during the postoperative period. Pathologic examination confirmed rupture of the inflow conduit (Fig. 1).

PATIENT 2. A 35-year-old man with progressive deterioration as a result of dilative cardiomyopathy and recurrent ventricular arrhythmias (Lown IVb) underwent implantation of the TCI LVAD system. His condition had deteriorated steadily despite high-dose catecholamine ad- 


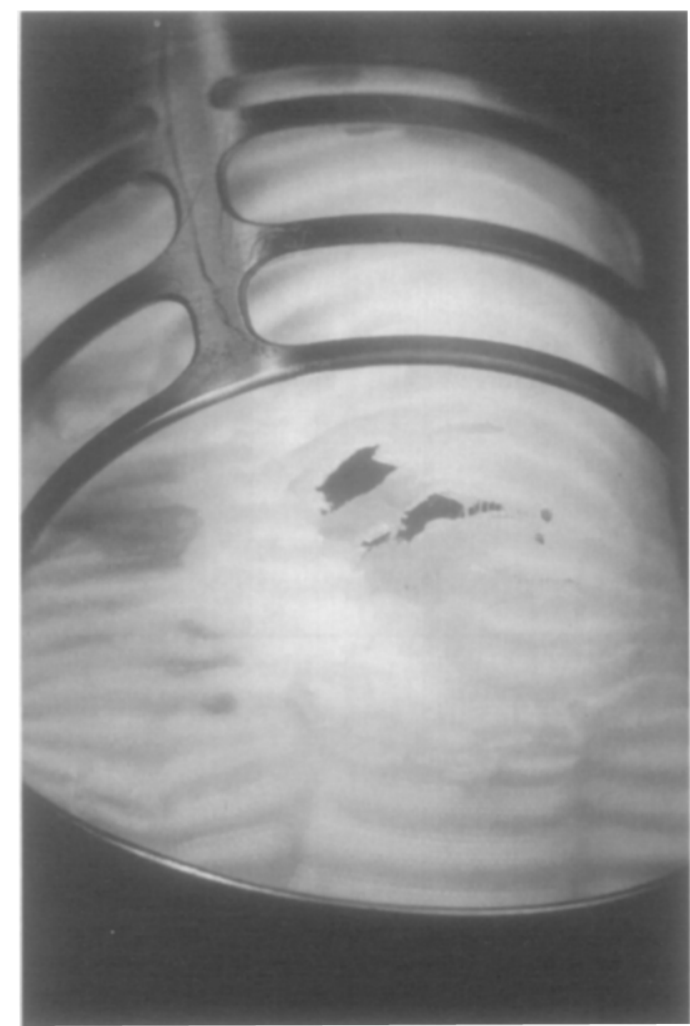

Fig. 1. Rupture of the inflow conduit in patient 1.

ministration and placement of an intraaortic balloon pump. The postoperative course was uneventful, and the patient was discharged to his home in excellent condition with an exercise capacity of $75 \mathrm{~W}$. After 147 days, a suitable donor heart became available and the patient was scheduled for transplantation. Intraoperatively, extensive adhesions rendered explantation of the LVAD difficult. When the inflow conduit was approached, a circumscribed encapsulated hematoma of approximately chicken egg size $(6 \times 3 \times 3 \mathrm{~cm})$ was evident originating from the conduit close to the inflow valve. With removal of the clots, a similar tear within the Dacron tube was visible. Inasmuch as the patient was already receiving extracorporeal circulation, the LVAD was immediately halted to prevent aspiration of air and resulting air embolism. The conduit was clamped and the transplant procedure completed in a standard fashion. The postoperative course was uneventful and the patient was discharged to his home (Fig. 2).

The assortment of LVADs demonstrates that no system currently guarantees maximal reliability and security for the patient. Many different materials have been used in fabrication, and ongoing clinical and laboratory research is associated with continuous device modification and improvement. Reports of mechanical failures are sparse. ${ }^{5}$ In 1988, a threaded outflow connector loosened in one patient, who required reoperation. Subsequently, the design was modified and a locking mechanism incorporated. ${ }^{6}$ Very recently, Mehta and Pae ${ }^{1}$ reported on a patient with erosion of the inlet cannula of the TCI system.

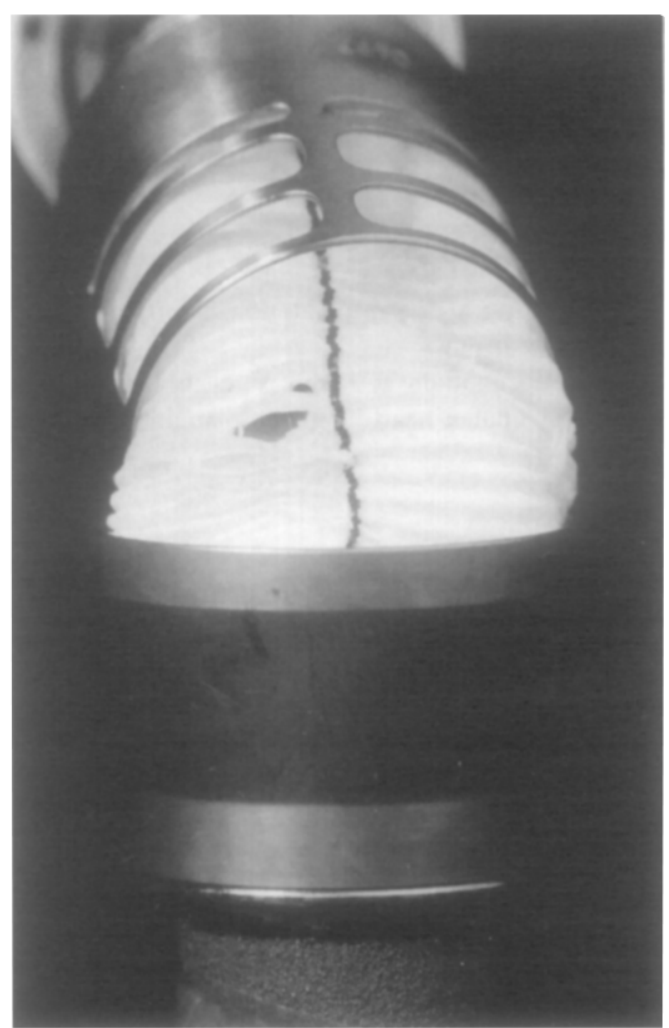

Fig. 2. Rupture of the inflow conduit in patient 2 .

Personal communications have revealed similar problems at other institutions. In our two patients, multiple transverse tears developed within the inflow conduit, presumably related to erosion of the Dacron tube by the edge of the covering metallic cage. Inasmuch as bleeding in the first patient became evident after mobilization, one may hypothesize that repetitive and inadequate bending of the conduit may have resulted in erosion of the Dacron tube. The adjacent inflow valve with its rigid anulus may additionally act as an anchor, thus increasing wall stress and promoting the laceration. We do not think that the Dacron tube is unsuitable, because valved Dacron conduits are not new and their durability has been proved by aortic operations.

It has been stated that the shorter inflow cannula of the TCI system is more advantageous than that of the Novacor systems in terms of placing the pump in the upper portion of the abdomen, below the costal margin. ${ }^{7}$ It is possible that a longer inflow conduit may be less prone to bending forces during patient mobilization. Moreover, if rupture of the inflow conduit is suspected, preparation is hard to achieve during surgical revision and the short TCI inflow conduit renders exposure even more difficult. Apart from tremendous bleeding, aspiration of air through the lacerations may also seriously jeopardize the patient's condition, particularly the cerebral function, during subsequent transplantation or other surgical procedures. In this situation, extracorporeal circulation must be instituted immediately and the LVAD stopped before complete exploration. Aggressive surgical management is 
surely warranted, as stated by Mehta and Pae. ${ }^{1}$ Theoretically, inflow valve dysfunction may occur as well, even if it seems unlikely. The metallic sheath has since been redesigned and is now less mobile, because it is fixed to another metallic ring by a string.

In conclusion, rupture of the inflow conduit close to the inflow valve is a life-threatening complication of the TCI system with the mobile cage support, which occurs more often than expected. Possible mechanisms include multiple bending limited by the metallic cage support resulting from suboptimal placement, while the valvular anulus might be acting as an anchor. Patients with possible bleeding should receive aggressive treatment, even though exchange and replacement of the inflow conduit is a demanding task. The metallic sheath has recently been redesigned, and future patients may no longer be at risk for this complication.

\section{REFERENCES}

1. Mehta SM, Pae W. Erosion of inlet cannula of left ventricular assist device manifested as innocuous bleeding in stable pa- tient: lessons learned in prevention of catastrophic consequences. J Thorac Cardiovasc Surg 1996;112:544-5.

2. Scheld HH, Hammel D, Schmid C, et al. Beating heart implantation of a wearable NOVACOR left-ventricular assist device. Thorac Cardiovasc Surg 1996;44:62-6.

3. Guilmet D, Bachet J, Goudot B, Laurian C, Gigou F, Bical O, et al. Use of biological glue in acute aortic dissection. $\mathrm{J}$ Thorac Cardiovasc Surg 1979;77:516-21.

4. Bachet J, Goudot B, Teodori G, Brodaty D, Dubois C, de Lentdecker $\mathrm{PH}$, et al. Surgery of type A acute aortic dissection with Gelatine-Resorcine-Formol biological glue: a twelve-year experience. J Cardiovasc Surg 1990;13:263-73.

5. Noon GP, Ball JW. Postcardiotomy mechanical ventricular support: decreasing morbidity and mortality. Ann Thorac Cardiovasc Surg 1996;2:15-20.

6. Frazier OH, Rose EA, Macmanus Q, et al. Multicenter clinical evaluation of the HeartMate 1000IP left ventricular assist device. Ann Thorac Surg 1992;53:1080-90.

7. McCarthy PM, Wang N, Vargo R. Preperitoneal insertion of the HeartMate 1000 IP implantable left ventricular assist device. Ann Thorac Surg 1994;57:634-8.

\section{NODULAR PULMONARY AMYLOIDOSIS}

Francis J. Podbielski, MD, Darren G. Nelson, MD, Gurney F. Pearsall, Jr., MD, Guillermo D. Marquez, MD, and Mark M. Connolly, MD, FACS, Chicago, Ill.

Pulmonary amyloid deposition generally occurs with concurrent primary systemic amyloidosis. Localized forms of pulmonary amyloidosis are rare and appear most frequently as an incidental lower lobe finding in chest radiographs. Tissue for diagnosis can be acquired by bronchoscopic, computed tomography-guided, thoracoscopic, or open biopsy techniques. Our patient had a nonproductive cough and multiple new lung nodules that led to open biopsy and diagnosis.

Although pulmonary amyloid is frequently found at autopsy as a sequela of primary systemic amyloidosis, cardiac failure resulting from amyloid deposition contributes to the patient's death in the majority of cases. Median survival time for 21 patients with this condition in a series reported by Utz, Swensen, and Gertz ${ }^{1}$ was 16 months.

From the Department of Surgery, Columbus Hospital, Chicago, Ill.

Received for publication Jan. 7, 1997; accepted for publication Jan. 28, 1997.

Address for reprints: Francis J. Podbielski, MD, Department of Surgery, Columbus Hospital, 2520 N. Lakeview Ave., Chicago, IL 60614.

J Thorac Cardiovasc Surg 1997;114:289-91

Copyright (C) 1997 by Mosby-Year Book, Inc.

$0022-5223 / 97 \$ 5.00+0 \quad \mathbf{1 2 / 5 4 / 8 0 7 3 3}$
Twelve percent to $25 \%$ of patients with systemic amyloid disease have multiple myeloma.

Pulmonary amyloid deposition not associated with systemic disease occurs in three anatomic distributions: tracheobronchial, parenchymal, and senile (or diffuse). Dyspnea, cough, and hemoptysis are symptoms of tracheobronchial amyloidosis, with the average patient age being between 53 and 62 years. Management strategies include observation, bronchoscopic resection, laser ablation, and lung resection. The senile or diffuse form is generally asymptomatic. In one autopsy series ${ }^{2}$ diffuse amyloidosis was present in approximately $10 \%$ of patients older than age 80 years and in $50 \%$ of patients older than age 90 . The localized parenchymal form of the disorder is found in fewer than half of all patients with isolated pulmonary amyloid.

Clinical summary. A 65-year-old woman had had a nonproductive cough for 2 months. She denied fever, night sweats, weight loss, and hemoptysis. Past medical history included mild hypothyroidism treated with oral levothyroxine, no exposure to chemicals or asbestos, and a history of working as a registered nurse in a tuberculosis sanitorium in the $1950 \mathrm{~s}$, with a positive purified protein derivative (PPD) tuberculin skin reaction when last tested in 1968. A chest radiograph performed 4 years before presentation in preparation for an orthopedic procedure showed several small 